\title{
Influencing Factors Analysis of Facial Nerve Function after the Microsurgical Resection of Acoustic Neuroma
}

\author{
WenMing Hong, M.D., ${ }^{1}$ HongWei Cheng, M.D., ${ }^{1}$ XiaoJie Wang, M.D., ${ }^{2}$ ChunGuo Feng, M.D. ${ }^{3}$ \\ Departments of Neurosuregery, Pathology, ${ }^{2}$ Neurosuregery, ${ }^{3}$ First Affliated Hospital, AnHui Medical Univesity, Hefei, China
}

Objective : To explore and analyze the influencing factors of facial nerve function retainment after microsurgery resection of acoustic neurinoma.

Methods : Retrospective analysis of our hospital 105 acoustic neuroma cases from October, 2006 to January 2012, in the group all patients were treated with suboccipital sigmoid sinus approach to acoustic neuroma microsurgery resection. We adopted researching individual patient data, outpatient review and telephone followed up and the House-Brackmann grading system to evaluate and analyze the facial nerve function.

Results : Among 105 patients in this study group, complete surgical resection rate was $80.9 \%(85 / 105)$, subtotal resection rate was $14.3 \%(15 / 105)$, and partial resection rate $4.8 \%(5 / 105)$. The rate of facial nerve retainment on neuroanatomy was $95.3 \%(100 / 105)$ and the mortality rate was $2.1 \%(2 / 105)$. Facial nerve function when the patient is discharged from the hospital, also known as immediate facial nerve function which was graded in House-Brackmann : excellent facial nerve function (House-Brackmann I-II level) cases accounted for 75.2\% (79/105), facial nerve function III-IV level cases accounted for 22.9\% (24/105), and V-VI cases accounted for $1.9 \%(2 / 105)$. Patients were followed up for more than one year, with excellent facial nerve function retention rate (H-B I-Il level) was $74.4 \%$ (58/78).

Conclusion : Acoustic neuroma patients after surgery, the long-term ( $\geq 1$ year) facial nerve function excellent retaining rate was closely related with surgical proficiency, post-operative immediate facial nerve function, diameter of tumor and whether to use electrophysiological monitoring techniques; while there was no significant correlation with the patient's age, surgical approach, whether to stripping the internal auditory canal, whether there was cystic degeneration, tumor recurrence,whether to merge with obstructive hydrocephalus and the length of the duration of symptoms.

Key Words : Acoustic neuroma - Facial nerve function - Sigmoid sinus approach · Electrophysiological monitoring · Keyhole · Internal acoustic meatus.

\section{INTRODUCTION}

Acoustic neuroma which mostly originates from vestibulocochlear nerve is the most common tumor in the cerebellopon- tine angle (CPA), also known as vestibular nerve Schwann cell tumor, and less than $10 \%$ of the tumor originate in the cochlear nerve. Acoustic neuroma accounting for $85-92 \%$ of cerebellopontine angle tumors, accounted for $93.1 \%$ of intra-

- Received : July 19, 2013 •Accepted : September 29, 2013

- Address for reprints : HongWei Cheng, M.D.

Department of Neurosurgery, Fist Affliated Hospital, AnHui Medical Univesity, Hefei 230032, China

Tel : +86-18916590701, Fax : +86-055162922123, E-mail : 524594636@qq.com

This is an Open Access article distributed under the terms of the Creative Commons Attribution Non-Commercial License (http://creativecommons.org/licenses/by-nc/4.0) which permits unrestricted non-commercial use, distribution, and reproduction in any medium, provided the original work is properly cited. 
cranial nerve Schwann cell tumor, and accounting for 7.79$10.64 \%$ of intracranial tumors ${ }^{18)}$. With the growth of tumor, it can be oppressive to the outer side of the pons and the leading edge of the cerebellum, which caused cerebellopontine angle tumor syndrome which included hearing changes, tinnitus, vestibular dysfunction, headache, cerebellar ataxia and dysfunction of facial nerve, trigeminal nerve and posterior group cranial nerve, etc. Moreover, it can lead to serious damage to the life quality of the patients, even endanger patient safety.

The cerebellopontine angle is a triangular space area composed by cerebellum, pons and oblongata and petrous bone (internal auditory meatus), and it is located in the both sides of posterior cranial fossa anterior. The triangular area has trigeminal nerve, vestibulocochlear nerve, glossopharyngeal nerve, vagus nerve and accessory nerve from top to bottom; from the outside to the inside is vestibulocochlear nerve, labyrinthine artery, anterior inferior cerebellar artery and abducent nerve, facial nerve. Acoustic neuroma is located in this space, because the region is deep, and has many important structures, and specifically closely related with pons, cerebellum and posterior cranial nerves, which makes the treatment of acoustic neuroma face huge challenge to cut all tumour and protect neural function. Operation treatment mainly contained three kinds of operation approach : suboccipital retrosigmoid approach (RSC), the middle cranial fossa approach (MFC), translabyrinthine approach (TLC), in which the RSC could show a wide range, so it is for all kinds of the size of the tumor, and the total removal rate is was high. Also, the internal auditory canal can be opened according to the actual needs, which is easy to early identification facial nerve from the internal auditory canal. Therefore, many neurosurgeons used this surgical approach ${ }^{4,7,12,17)}$.

In recent years, there is no apparent difficulty for acoustic neuroma resection with the development of microsurgical technique, endoscope, neural electrophysiological monitoring and neuronavigation technique. Difficulties and challenges of operation are how to obtain the maximum tumor resection while at the same time to get the surrounding normal tissue maximum protection, and long-term retention of facial nerve function $^{4)}$. The authors collected total of 105 cases with acoustic neuroma cases from October 2006 to January 2012, with 78 patients with long-term follow-up as the main research object to explore the influence factors of facial nerve function retention after acoustic neuroma microsurgery excision in suboccipital retrosigmoid approach.

\section{MATERIALS AND METHODS}

\section{General case information}

From October 2006 to January 2012, we retrospectively analyzed the 105 cases of acoustic neuroma operation patients in the department of neurosurgery in our hospital. In this group, we found the patients' age was from 14 to 73 years old, the average age was 48.7 years old; male was 41 cases, female was 64 cases; the left acoustic neuroma was 59 cases, right side was 46 cases. Preoperative symptom duration time was from 1 to 360 months, average was 42 months. Large acoustic neuroma (diameter $\geq 30 \mathrm{~mm}$ ) accounted for $90.5 \%$ (95/105). In this study group, complete surgical resection rate was $80.9 \%$ (85/105), subtotal resection rate was $14.3 \%$ (15/105), and partial resection rate was $4.8 \%(5 / 105)$. The rate of facial nerve retainment on neuroanatomy was $95.3 \%(100 / 105)$ and the mortality rate was $2.1 \%$ (2/105). At the end of follow-up, 3 cases had tumor recurrence. All patients routine taken orally nimodipine tablets (1\# Tid), mecobalamin tablets (1\# Tid), more than three months. We followed up 78 cases whose long-term facial nerve function means follow-up time $\geq 1$ year in the group. The 78 cases were as the main study object to explore the influencing factors of facial nerve function.

\section{Clinical manifestations}

There were a total of 71 patients (91\%) with hearing impairment as a typical clinical presentation; 34 cases (43.6\%) with facial numbness; 10 cases $(9.52 \%)$ with facial nerve dysfunction; 20 cases $(25.6 \%)$ in performance of headache and dizziness symptoms; 15 cases $(14.6 \%)$ with muscle strength decreased; 25 cases (23.9\%) with ataxia; 12 cases (15.4\%) showed hoarseness and dysphagia; and 5 cases $(6.4 \%)$ with vision reduced.

\section{Imaging manifestations}

All patients before operation were performed head MRI examination, in which 69 cases underwent brain CT examination, 78 cases with internal auditory canal plain film examination. In 69 patients examined by cranial CT cases, 7 cases showed low density lesions, 26 cases showed a high density or 
slight high density, 36 cases showed mixed density. The size of the tumor : 7 cases with diameter less than $30 \mathrm{~mm}$; 18 cases' diameter was 30-39 mm; 27 cases' diameter was $40-49 \mathrm{~mm}$, 26 cases' diameter was more than $50 \mathrm{~mm}$. In the 78 cases with internal auditory canal radiographs, 67 cases showed internal auditory canal enlargement. Acoustic neuroma in T1 weighted magnetic resonance images showed isointensity or slightly longer signal, T2 weighted magnetic resonance imaging showed isointensity or slightly longer signal. The study group of patients with MRI, CT and internal auditory canal radiography showed that 36 cases with supratentorial ventricles expand (46.2\%), 67 cases with the internal auditory canal enlarged (64.1\%), 3 cases with acoustic neuroma expand to the middle cranial fossa $(3.8 \%)$.

\section{Surgical methods}

The patients were treated by suboccipital retrosigmoid approach to resect tumors. Five patients with large tumors $(>6.0$ $\mathrm{cm}$ ) had hydrocephalus and tonsillar hernia, so emergency ventricular puncture and drainage to reduce intracranial pressure were performed before craniotomy operation. After satisfactory anesthesia, patients were in the lateral decubitus position, the head elevated $15^{\circ}$, slightly deflect to the uninjured side, mastoid medial edge at the highest point, occipital squa$\mathrm{ma}$ is the horizontal part, operation incision was $1.5 \mathrm{~cm}$ to the inside of star point, and longitudinal incision was $6 \mathrm{~cm}$ long. We drilled a bone window about $2.5-3 \mathrm{~cm}$ to the mastoid rear in keyhole approach, whose upper outer edge to the transverse sinus and outer edge to the sigmoid sinus; while the bone flap diameter of conventional craniotomy expanded to about 4.5 $\mathrm{cm}$. The operation microscope was placed after the dura mater was cut parallel to the bone window edge of "1" shape, then open the arachnoid to slowly released cerebrospinal fluid and use mannitol to reduce brain pressure. After cerebellar hemisphere retraction and operative field fully exposed, we handled the arachnoid and the tumor. We paid special attention to avoid injury of facial nerve and to protect important vascular in this stage. In the tumor treatment after filling on crossing ing tumors Internal auditory canal should be grinded if the tumor growth is inward to internal auditory canal. Patients were treated by routine craniotomy were 21 cases, while the keyhole craniotomy were 57 cases; 53 cases with monitoring of electrophysiology; 31 cases with internal auditory meatus removal.

\section{Methods of follow-up and facial nerve function's evaluation}

All patients were followed with careful review of medical records including symptoms, neurological signs, imaging data and questionnaire. Evaluation of facial nerve function is based on control of facial expressions (including five independent, eyes closed, gills drums, whistles, teeth, wrinkled forehead), and control of facial symmetry in the resting and movement state. The results associated with the classification of facial nerve function were based on House-Brackmann grading system. All data were handled by SPSS version 18.0 for statistical analysis (SPSS Inc., Chicago, IL, USA), and $p<0.05$ was considered statistically significant.

Table 1. The relationship between long-term and early facial nerve function

\begin{tabular}{lccccc}
\hline \multirow{2}{*}{ Early } & \multicolumn{2}{c}{ Long-term (>1 year) } & \multicolumn{2}{c}{ Total } \\
\cline { 2 - 5 } & H-B I & H-B II & H-B III & 0 & 20 \\
H-B I & 16 & 4 & 0 & 1 & 42 \\
H-B II & 13 & 25 & 3 & 4 & 9 \\
H-B III & 0 & 0 & 5 & 5 & 7 \\
H-B IV & 0 & 0 & 10 & 10 & 78 \\
\hline Total & 29 & 29 & 2 & \\
\hline
\end{tabular}

This table shows the relation between facial nerve function of postoperative long-term ( $>1$ years) and early facial nerve function, using Spearman correlation analysis indicated : the early postoperative facial nerve function and long-term facial nerve function shows close correlation (correlation coefficient rs $=0.702, p<0.05)$. H-B : House-Brackmann 


\section{RESULT}

The relationship between facial nerve function of postoperative long-term (>1 year) and early facial nerve function (Table 1)

The relationship between tumor size and longterm postoperative facial nerve function (Table 2)

Tumors were divided into four groups according to the diameter : 1) <30 mm; 2) 30-39 mm; 3) 40-49 mm; 4)>50 $\mathrm{mm} .7$ cases with the tumor diameter of $30 \mathrm{~mm} ; 18$ cases with the tumor diameter of $30-39 \mathrm{~mm} ; 27$ cases with the tumor diameter of 40-49 cm, 26 cases with the tumor diameter more than $\geq 50 \mathrm{~mm}$.

The relationship between intraoperative electrophysiological monitoring and postoperative longterm facial nerve function (Table 3)

According to whether use of intraoperative neurophysiological monitoring, the study group was divided into two groups : monitoring group and non monitoring group. The monitor- ing group was 53 cases; no monitoring group was 25 cases, and the details were shown in Table 3.

\section{The relationship between tumor recurrence and long-term facial nerve function}

According to whether the patients with recurrence of tumor, the study cases were divided into two groups : 75 cases without tumor recurrence; 3 cases with tumor recurrence. Details of the relationship between tumor recurrence and the postoperative long-term facial nerve function were shown in Table 4.

\section{The relationship between tumor cystic degen- eration and long-term postoperative facial nerve function}

According to whether the tumor cystic degeneration, the study cases were divided into two groups : 35 cases with tumor cystic degeneration; 43 cases without tumor cystic degeneration. Details of the relationship between tumor cystic degeneration and the postoperative long-term facial nerve function were shown in Table 5.

Table 2. The relationship between tumor size and long-term postoperative facial nerve function

\begin{tabular}{|c|c|c|c|c|c|c|}
\hline \multirow{2}{*}{$\begin{array}{l}\text { Tumor diameter } \\
(\mathrm{mm})\end{array}$} & \multicolumn{4}{|c|}{ Postoperative ling-term facial nerve function } & \multirow{2}{*}{ Total } & \multirow{2}{*}{$\begin{array}{l}\text { Excellent } \\
\text { rate (\%) }\end{array}$} \\
\hline & H-B I & H-B II & H-B III & H-B IV & & \\
\hline$<30$ & 4 & 3 & 0 & 0 & 7 & 100 \\
\hline $30-39$ & 8 & 10 & 0 & 0 & 18 & 100 \\
\hline $40-49$ & 11 & 12 & 3 & 1 & 27 & 85.2 \\
\hline$>50$ & 3 & 7 & 10 & 6 & 26 & 38.5 \\
\hline Total & 26 & 32 & 13 & 7 & 78 & 74.4 \\
\hline
\end{tabular}

The data was used by chi-square test : the excellent preservation of facial nerve function shows correlation with the tumor diameter ( $p=0.001)$. The rate of facial nerve function was higher if the diameter of tumor was smaller. H-B : House-Brackmann

Table 3. The relationship between intraoperative electrophysiological monitoring and long-term postoperative facial nerve function

\begin{tabular}{|c|c|c|c|c|c|c|}
\hline \multirow{2}{*}{$\begin{array}{l}\text { Intraoprative } \\
\text { lectrophysiological } \\
\text { monitoring }\end{array}$} & \multicolumn{4}{|c|}{ Postoperative ling-term facial nerve function } & \multirow{2}{*}{ Total } & \multirow{2}{*}{$\begin{array}{c}\text { Excellent } \\
\text { rate (\%) }\end{array}$} \\
\hline & H-B I & H-B II & H-B III & H-B IV & & \\
\hline Yes & 28 & 16 & 5 & 4 & 53 & 83.1 \\
\hline No & 6 & 8 & 6 & 5 & 25 & 56.0 \\
\hline Total & 34 & 24 & 11 & 9 & 78 & 74.4 \\
\hline
\end{tabular}

The data was used rank convert of non-parametric tests, and the result suggests that there is a statistically significant difference in the excellent rate of long-term postoperative facial nerve function between intraoperative electrophysiological monitoring group and no electrophysiological monitoring group ( $p=0.044$ ), which indicates the excellent rate of intraoperative electrophysiological monitoring group was higher. H-B : House-Brackmann 


\section{The relationship between surgical approach and long-term postoperative facial nerve function}

According to the surgical approach, the study cases were divided into two groups : routine craniotomy were 21 cases, while the keyhole craniotomy were 57 cases. Details of the relationship between surgical approach and long-term postoperative facial nerve function were shown in Table 6.

\section{The relationship between grind internal acoustic meatus and long-term postoperative facial nerve function}

According to whether grind the internal acoustic meatus, the study cases were divided into two groups : 35 cases with grinding the internal acoustic meatus, while 43 cases without grinding. Details of the relationship between grind internal acoustic meatus and long-term postoperative facial nerve function were shown in Table 7.

\section{The relationship between obstructive hydroceph- alus and long-term postoperative facial nerve function}

According to whether the patients with obstructive hydrocephalus, the study cases were divided into two groups : 36 cases with obstructive hydrocephalus, while 42 cases without obstructive hydrocephalus. Details of the relationship between obstructive hydrocephalus and long-term postoperative facial nerve function were shown in Table 8 .

Table 4. The relationship between tumor recurrence and long-term postoperative facial nerve function

\begin{tabular}{|c|c|c|c|c|c|c|}
\hline \multirow{2}{*}{$\begin{array}{l}\text { Tumor } \\
\text { recurrence }\end{array}$} & \multicolumn{4}{|c|}{ Postoperative ling-term facial nerve function } & \multirow{2}{*}{ Total } & \multirow{2}{*}{ Excellent rate (\%) } \\
\hline & H-B I & H-B II & H-B III & H-B IV & & \\
\hline Yes & 0 & 1 & 1 & 1 & 3 & 33.3 \\
\hline No & 26 & 31 & 11 & 7 & 75 & 76.0 \\
\hline Total & 26 & 32 & 12 & 8 & 78 & 74.4 \\
\hline
\end{tabular}

The data was used rank convert of non-parametric tests, and the result suggests that there is no statistically significant difference in the excellent rate of long-term postoperative facial nerve function between recurrence group and no recurrence group ( $p=0.340)$. $\mathrm{H}-\mathrm{B}$ : House-Brackmann

Table 5. The relationship between tumor cystic degeneration and long-term postoperative facial nerve function

\begin{tabular}{|c|c|c|c|c|c|c|}
\hline \multirow{2}{*}{$\begin{array}{l}\text { Tumor cystic } \\
\text { degeneration }\end{array}$} & \multicolumn{4}{|c|}{ Postoperative ling-term facial nerve function } & \multirow{2}{*}{ Total } & \multirow{2}{*}{ Excellent rate (\%) } \\
\hline & H-B I & H-B II & H-B III & H-B IV & & \\
\hline Yes & 13 & 11 & 7 & 4 & 35 & 68.6 \\
\hline No & 13 & 21 & 4 & 5 & 43 & 79.1 \\
\hline Total & 26 & 32 & 11 & 8 & 78 & 74.4 \\
\hline
\end{tabular}

The data were used rank convert of non-parametric tests, and the result suggests that there is no statistically significant difference in the excellent rate of long-term postoperative facial nerve function between tumor cystic degeneration group and no cystic degeneration group ( $p=0.352)$. H-B : HouseBrackmann

Table 6. The relationship between surgical approach and long-term postoperative facial nerve funtion

\begin{tabular}{|c|c|c|c|c|c|c|}
\hline \multirow{2}{*}{$\begin{array}{l}\text { Surgical } \\
\text { approach }\end{array}$} & \multicolumn{4}{|c|}{ Postoperative ling-term facial nerve function } & \multirow{2}{*}{ Total } & \multirow{2}{*}{ Excellent rate (\%) } \\
\hline & H-B I & H-B II & H-B III & H-B IV & & \\
\hline Routine & 7 & 8 & 3 & 3 & 21 & 71.4 \\
\hline Keyholg & 19 & 24 & 9 & 5 & 57 & 75.4 \\
\hline Total & 26 & 32 & 12 & 8 & 78 & 74.4 \\
\hline
\end{tabular}

The data were used rank convert of non-parametric tests, and the result suggests that there is no statistically significant difference in the excellent rate of long-term postoperative facial nerve function between routine craniotomy group and keyhole craniotomy group ( $p=0.911)$. H-B : House-Brackmann 
Table 7. The relationship between grind internal acoustic meatus and long-term postoperative facial nerve function

\begin{tabular}{|c|c|c|c|c|c|c|}
\hline \multirow{2}{*}{$\begin{array}{l}\text { Grind internal } \\
\text { acoustic meatus }\end{array}$} & \multicolumn{4}{|c|}{ Postoperative ling-term facial nerve function } & \multirow{2}{*}{ Total } & \multirow{2}{*}{ Excellent rate (\%) } \\
\hline & H-B I & H-B II & H-B III & H-B IV & & \\
\hline Yes & 12 & 13 & 7 & 3 & 35 & 71.4 \\
\hline No & 17 & 16 & 6 & 4 & 43 & 76.7 \\
\hline Total & 26 & 29 & 13 & 7 & 78 & 74.4 \\
\hline
\end{tabular}

The data were used rank convert of non-parametric tests, and the result suggests that there is no statistically significant difference in the excellent rate of long-term postoperative facial nerve function between grind the internal acoustic meatus group and no grinding group ( $p=0.902)$. H-B : HouseBrackmann

Table 8. The relationship between obstructive hydrocephalus and long-term postoperative facial nerve function

\begin{tabular}{|c|c|c|c|c|c|c|}
\hline \multirow{2}{*}{$\begin{array}{l}\text { Obstructive } \\
\text { hydrocepharlus }\end{array}$} & \multicolumn{4}{|c|}{ Postoperative ling-term facial nerve function } & \multirow{2}{*}{ Total } & \multirow{2}{*}{ Excellent rate (\%) } \\
\hline & H-B I & H-B II & H-B III & H-B IV & & \\
\hline Yes & 11 & 15 & 7 & 3 & 36 & 72.2 \\
\hline No & 15 & 17 & 5 & 5 & 42 & 76.2 \\
\hline Total & 26 & 32 & 12 & 8 & 78 & 74.4 \\
\hline
\end{tabular}

The data were used rank convert of non-parametric tests, and the result suggests that there is no statistically significant difference in the excellent rate of long-term postoperative facial nerve function between obstructive hydrocephalus group and no obstructive hydrocephalus group ( $p=0.773$ ). $\mathrm{H}-\mathrm{B}$ : House-Brackmann

Table 9. The relationship between patients' age and long-term postoprative facial nerve function

\begin{tabular}{|c|c|c|c|c|c|c|}
\hline \multirow{2}{*}{ Age (Years) } & \multicolumn{4}{|c|}{ Postoperative ling-term facial nerve function } & \multirow{2}{*}{ Total } & \multirow{2}{*}{ Excellent rate (\%) } \\
\hline & H-B I & H-B II & H-B III & H-B IV & & \\
\hline $0-20$ & 1 & 2 & 1 & 0 & 4 & 75.0 \\
\hline $21-40$ & 9 & 11 & 3 & 3 & 26 & 76.9 \\
\hline $41-60$ & 11 & 15 & 7 & 3 & 36 & 72.2 \\
\hline$>60$ & 4 & 5 & 1 & 2 & 12 & 74.4 \\
\hline Total & 26 & 33 & 12 & 8 & 78 & 74.4 \\
\hline
\end{tabular}

The data were used the ordinal data linear trend test analysis, and the result suggests that there is no statistically significant difference in the excellent rate of long-term postoperative facial nerve function between the groups $\left(\chi^{2}=2.534, p=0.980\right)$. H-B : House-Brackmann

\section{The relationship between patients' age and long- term postoperative facial nerve function}

According to the patients' age, the study cases were divided into four groups : 1) 0-20 years old, 2) 21-40 years old, 3) 41-60 years old, and 4) >60 years old. Details of the relationship between patients' age and long-term postoperative facial nerve function were shown in Table 9.

\section{The relationship between duration of symptoms before surgery and long-term postoperative fa- cial nerve function}

According to the duration of symptoms before surgery, the study cases were divided into four groups : 1) $\leq 24$ months, 2) 25-48 months, 3) 49-72 months, and 4) $\geq 72$ months. Details of the relationship between duration of symptoms and longterm postoperative facial nerve function were shown in $\mathrm{Ta}-$ ble 10 .

\section{DISCUSSION}

Each patient was evaluated every three months. We evaluated the facial nerve function of all follow-up outpatients and kept records with digital photo mode.

In this study, through the case retrieval, and combined with 
Influencing Factors Analysis of Facial Nerve Function I Hong WM, et al.

Table 10. The relationship between duration of symptoms before surgery and long-term postoperative facial nerve function

\begin{tabular}{|c|c|c|c|c|c|c|}
\hline \multirow{2}{*}{$\begin{array}{l}\text { Duration } \\
\text { (months) }\end{array}$} & \multicolumn{4}{|c|}{ Postoperative ling-term facial nerve function } & \multirow{2}{*}{ Total } & \multirow{2}{*}{ Excellent rate (\%) } \\
\hline & H-B I & H-B II & H-B III & H-B IV & & \\
\hline$<24$ & 17 & 19 & 7 & 4 & 47 & 76.6 \\
\hline $25-48$ & 7 & 8 & 5 & 1 & 21 & 71.4 \\
\hline $49-72$ & 3 & 2 & 1 & 1 & 7 & 71.4 \\
\hline$>72$ & 1 & 1 & 1 & 0 & 3 & 66.7 \\
\hline Total & 28 & 30 & 14 & 6 & 78 & 74.4 \\
\hline
\end{tabular}

The data were used the ordinal data linear trend test analysis, and the result suggests that there is no statistically significant difference in the excellent rate of long-term postoperative facial nerve function between the groups $\left(\chi^{2}=2.382, p=0.984\right)$. It indicates that there is no significant correlation between duration of symptoms before surgery and long-term postoperative facial nerve function. H-B : House-Brackmann

the related literature, we found that complete tumor resection was the key point to avoid the recurrence of the tumor after operation, and also to avoid second injury of facial nerve function after the operation of the recrudescent tumor ${ }^{7,18}$. Tumor recurrence often face the operation once again, which may further increase the damage of facial-acoustic nerve and lead to more serious injury of facial nerve function. But in our study, the data showed that there was no obvious statistical difference between tumor recurrence group and non-recurrence group in long-term postoperative facial nerve function $(p=0.340)$. The reasons for this phenomenon may be, first, operating skill of the surgeon. If the surgeon had good operating skill, the second operation did not increase the injury of facial nerve function. Second reason may be the small number of cases, so the extrapolation of the study was unkown. At the same time, we found that postoperative facial nerve anatomy retention rate was high $(95.3 \%)$, but the rate of postoperative excellent facial nerve function (House Brackmann I-II) was only $75.2 \%$ (79/105), which was to say the facial nerve function and facial nerve anatomy retention rate were not necessarily in the same level. Investigate its reason may be that ${ }^{12,17)}$ : first, some electric coagulation thermal injury of facial nerve could make its anatomy seem normally in the operation, but its function may have been damaged; second, some blood vessels for nutrition nerve may not be protected well during operation, which may cause postoperative nerve injury of ischemia and hypoxia. We know that cerebral vascular distribution is important to the nerver funtion ${ }^{8,15)}$. Therefore, when the tumor resection underwent retrosigmoid approach, we should pay attention to the following problems : 1) in the process of separating the tumor and pons, we must be always along the two tissue interface, first to separate arachnoid of tumor surface while must protect peripheral nerve and blood vessel. Then block resection in tumor capsule, but it must not be forced to pursue a full cut, otherwise easily lead to brain stem injury; 2) do not use electrocoagulation random, and we must flush cooling with saline when use bipolar coagulation to in order to avoid heat damage of peripheral nerve tissue; 3 ) open brain cistern to release cerebrospinal fluid was very important, the operation steps need to be patient, must make full retraction of cerebellum and slightly pull that can reveal the cerebellopontine angle and get enough operation space; and 4) the operator must have good technology of neurosurgery operation.

As to the choice of surgical approach, the trend is minimally invasive operation, while the keyhole technology is a symbol of minimally invasive neurosurgery. The keyhole operation was guaranteed implementation along with the development of endoscopy and navigation technology ${ }^{2,4,16,21,23)}$. In the process of craniotomy, bone window less than $3 \mathrm{~cm}$ is called the keyhole which is direct and accurate path and could avoid excess of craniotomy part in routine operation, as far as possible to arrived at the lesion site non-invasively and not exposed no lesion area. The advantages of keyhole ${ }^{3,9,14)}: 1$ ) the skin incision is small, which can maximize the retention of the patient's appearance; 2) craniotomy range is small, which can reduce excess of craniotomy part so as to minimize the normal brain tissue exposure and interference; 3) the path is direct and accurate and made full use of normal intracranial anatomy space, which can reduce the traction of brain, postoperative brain edema, brain contusion, and even the incidence of intracerebral hematoma; 4) it also reduces postoperative epilepsy, bleeding and other complications. And the postoperative reaction was light, patients are quickly recover, cost is low with 
good effect. Some research had shown that posterior suboccipital keyhole approach is more effective than conventional surgical approach in treatment of the cerebellopontine angle lesions. But our study showed that there was no statistically significant difference in the excellent rate of long-term postoperative facial nerve function between routine craniotomy group and keyhole craniotomy group ( $p=0.911$ ).

Further studies showed that tumor volume was related with the effect of operation ${ }^{13,18,22,25,26)}$. The foreign bulk case studies $^{5,6)}$ displayed that if the tumors were smaller, the postoperative facial nerve function was better. From 78 follow-up cases of this group, we can see that the excellent rate of long-term facial nerve function ( $\geq 1$ years after operation) would decline, as the tumors' volume increased, which showed statistical significance between postoperative long-term facial nerve function and tumor's diameter $(p=0.001)$. It also coincided with the foreign related research.

In addition, with the progress of science and technology, the electrical physiological monitoring technology constantly applied to the operation of neuroma ${ }^{28)}$. This technique helps to improve the rate of facial nerve preservation. Some studies ${ }^{2029)}$ have also suggested that monitoring of facial EMG in surgery can help surgeon early identify the walking direction of the facial nerve, and confirm whether the facial nerve structure was complete after facial nerve tumor resection, which had important significance to the retention of the facial nerve function. According to whether use of intraoperative neurophysiological monitoring, the study group was divided into two groups : monitoring group and non monitoring group. Through the data comparison, the excellent rate of postoperative long-term facial nerve function with electric physiological monitoring was significantly higher than those patients without the use of electrophysiological monitoring. It also confirmed the positive significance of the electrophysiological monitoring at home and abroad.

From the literature review, we found that foreign data showed postoperative long-term function of facial nerve was related with and cystic change of acoustic neuroma, obstructive hydrocephalus, preoperative radiotherapy and postoperative vasopressor therapy to patients ${ }^{1,10,11,19,24,26,27)}$. Howerer, our study data showed that there was no statistical significance with cystic change and hydrocephalus $(p \geq 0.05)$. As to the preoperative radiotherapy, the research was unable to confirm the correlation of postoperative long-term function of facial nerve and preoperative radiotherapy due to all patients without radiotherapy before surgery.

\section{References}

1. Bartalena T, Leoni C, Trossello MP, Rinaldi MF, Cianfoni A, Caprara G, et al. : Hourglass cystic schwannoma of the trochlear nerve. Acta Biomed 81 : 147-150, 2010

2. Charalampaki P, Filippi R, Welschehold S, Perneczky A : Endoscope-assisted removal of colloid cysts of the third ventricle. Neurosurg Rev 29 : 72-79, 2006

3. Chen L, Chen LH, Ling F, Liu YS, Samii M, Samii A : Removal of vestibular schwannoma and facial nerve preservation using small suboccipital retrosigmoid craniotomy. Chin Med J (Engl) 123 : 274-280, 2010

4. Frasson L, Ko SY, Turner A, Parittotokkaporn T, Vincent JF, Rodriguez y Baena F : STING : a soft-tissue intervention and neurosurgical guide to access deep brain lesions through curved trajectories. Proc Inst Mech Eng H 224 : 775-788, 2010

5. Gharabaghi A, Samii A, Koerbel A, Rosahl SK, Tatagiba M, Samii M : Preservation of function in vestibular schwannoma surgery. Neurosurgery 60 (2 Suppl 1) : ONS124-ONS127; discussion ONS127-ONS128, 2007

6. Gjurić M, Wigand ME, Wolf SR : Enlarged middle fossa vestibular schwannoma surgery : experience with 735 cases. Otol Neurotol 22 : 223-230; discussion 230-231, 2001

7. Gurgel RK, Theodosopoulos PV, Jackler RK : Subtotal/near-total treatment of vestibular schwannomas. Curr Opin Otolaryngol Head Neck Surg $20: 380-384,2012$

8. Han JS, Lee JA, Kong DS, Park K : Delayed cranial nerve palsy after microvascular decompression for hemifacial spasm. J Korean Neurosurg Soc 52 : 288-292, 2012

9. Khu KJ, Ng WH : Intraoperative swelling leading to neurological deterioration : an argument for large craniotomy in awake surgery for glioma resection. Clin Neurosci 16 : 886-888, 2009

10. Kondziolka D, Mousavi SH, Kano H, Flickinger JC, Lunsford LD : The newly diagnosed vestibular schwannoma : radiosurgery, resection, or observation? Neurosurg Focus 33 : e8, 2012

11. Limb CJ, Long DM, Niparko JK : Acoustic neuromas after failed radiation therapy : challenges of surgical salvage. Laryngoscope $115: 93-98$, 2005

12. Mazzoni A, Zanoletti $E$, Calabrese V : Hearing preservation surgery in acoustic neuroma : long-term results. Acta Otorhinolaryngol Ital 32 : 98-102, 2012

13. Oh T, Nagasawa DT, Fong BM, Trang A, Gopen Q, Parsa AT, et al. : Intraoperative neuromonitoring techniques in the surgical management of acoustic neuromas. Neurosurg Focus 33 : e6, 2012

14. Paladino J, Pirker N, Stimac D, Stern-Padovan R : Eyebrow keyhole approach in vascular neurosurgery. Minim Invasive Neurosurg 41 : 200-203, 1998 
15. Park HS, Chang DK, Han YM : Infranuchal infrafloccular approach to the more vulnerable segments of the facial nerve in microvascular decompressions for the hemifacial spasm. J Korean Neurosurg Soc 46 : 340-345, 2009

16. Park HS, Park SK, Han YM : Microsurgical experience with supraorbital keyhole operations on anterior circulation aneurysms. J Korean Neurosurg Soc 46 : 103-108, 2009

17. Porter RG, LaRouere MJ, Kartush JM, Bojrab DI, Pieper DR : Improved facial nerve outcomes using an evolving treatment method for large acoustic neuromas. Otol Neurotol 34 : 304-310, 2013

18. Samii M, Matthies C : Management of 1000 vestibular schwannomas (acoustic neuromas) : surgical management and results with an emphasis on complications and how to avoid them. Neurosurgery 40 : 1121; discussion 21-23, 1997

19. Scheller C, Richter HP, Engelhardt M, KÖenig R, Antoniadis G : The influence of prophylactic vasoactive treatment on cochlear and facial nerve functions after vestibular schwannoma surgery : a prospective and open-label randomized pilot study. Neurosurgery 61 : 92-97; discussion 97-98, 2007

20. Shchekut'ev GA, Shimanskiı̌ VN, Ogurtsova AA, Semenov MS : Identification of the cochlear nerve in surgical removal of vestibular schwannomas. Zh Vopr Neirokhir Im N N Burdenko (3) : 10-13; discussion 13-14, 2009

21. Shin D, Park J : Unruptured supraclinoid internal carotid artery aneurysm surgery : superciliary keyhole approach versus pterional approach. J Korean Neurosurg Soc 52 : 306-311, 2012

22. Somers $T$, Van Havenbergh $T$ : Multidisciplinary management of ves- tibular schwannomas : state of the art. B-ENT 8 : 235-240, 2012

23. Stadie AT, Reisch R, Kockro RA, Fischer G, Schwandt E, Boor $S$, et al. : Minimally invasive cerebral cavernoma surgery using keyhole approaches - solutions for technique-related limitations. Minim Invasive Neurosurg 52 : 9-16, 2009

24. Strauss C, Romstöck J, Fahlbusch R, Rampp S, Scheller C : Preservation of facial nerve function after postoperative vasoactive treatment in vestibular schwannoma surgery. Neurosurgery 59 : 577-584; discussion 577-584, 2006

25. Sughrue ME, Kaur R, Rutkowski MJ, Kane AJ, Yang I, Pitts LH, et al. : A critical evaluation of vestibular schwannoma surgery for patients younger than 40 years of age. Neurosurgery 67 : 1646-1653; discussion 1653-1654, 2010

26. Sun S, Liu A : Long-term follow-up studies of Gamma Knife surgery with a low margin dose for vestibular schwannoma. J Neurosurg 117 Suppl : 57-62, 2012

27. Yashar P, Zada G, Harris B, Giannotta SL : Extent of resection and early postoperative outcomes following removal of cystic vestibular schwannomas : surgical experience over a decade and review of the literature. Neurosurg Focus 33 : e13, 2012

28. Yi JS, Lee HJ, Lee HJ, Lee IW, Yang JH : Rat peripheral nerve regeneration using nerve guidance channel by porcine small intestinal submucosa. J Korean Neurosurg Soc 53 : 65-71, 2013

29. Youssef AS, Downes AE : Intraoperative neurophysiological monitoring in vestibular schwannoma surgery : advances and clinical implications.

Neurosurg Focus 27 : e9, 2009 